\title{
EL COLOR EN LA LITERATURA DEL MODERNISMO
}

\author{
José Luis BERNAL MUÑOZ
}

1 SINESTESIAS (El color de la música)

Una de las más habituales características de la literatura modernista es la utilización de las sinestesias, procedimiento consistente en producir sensaciones asociadas a un sentido a través de estímulos dirigidos a otro. Referente inevitable para las sinestesias modernistas es el de Émaux et Camées, Esmaltes y Camafeos, obra de Théophile Gautier de 1852 en la que el poeta utilizaba la sugestión de las joyas, esmaltes y piedras preciosas, para sugerir un lenguaje brillante y luminoso '.

Conviene no perder de vista que poco antes de que surja lo que estamos llamando modernismo los impresionistas, conocidos con este nombre ya desde 1874, están desarrollando sus teorías de la nueva pintura de la luz y del color. Buscaban estos artistas en sus pinturas no el paisaje, sino la «impresión» producida por el paisaje abandonando la realidad y entrando en un mundo idealista basado en las impresiones y las sensaciones. Pero tampoco hay que olvidar que los músicos franceses de la época como Rabel o Debussy también buscaban su inspiración en las mismas fuentes que los pintores, creando composiciones pictóricas como «Pasos sobre la nieve» o «Nocturno amarillo».

' En la obra El Simbolismo, edición de José Olivio Jiménez, Madrid, Taurus Ediciones, 1979, se incluye un erudito estudio de Iván Schulman (pp. 246 a 255) sobre las sinestesias, en el que aporta una enorme cantidad de datos y de investigaciones sobre la cuestión, desde las teorías de R.Ghil, O'Malley o Johansen, hasta curiosidades como las del jesuíta Louis Bertrand Castel que en el siglo XVIII inventó un clavecín de color para reproducir, mediante una armonía de colores, el placer creado por las notas musicales 
Como no podía ser de otra forma, los poetas franceses que podemos situar en los orígenes del simbolismo se ocuparon con interés y admiración de esta nueva escuela. Para dichos poetas la relación entre los colores, los sonidos, la música e incluso los perfumes tuvo una enorme importancia, siendo las Correspondances de Beaudelaire una de las mayores aportaciones al respecto que a su vez darían lugar a los estudios de René Ghil (Traité du verbe, 1886 y Méthode à l'oeuvre, 1891) para quien el sonido tiene color, importando poco el sentido de la palabra en el poema que estaría constituído por las palabras-música de un lenguaje músical. De esta forma se iría creando un universo de símbolos que permitiría sumergirse en las más vagas y borrosas emociones.

Entre los que se ocuparon de los pintores impresionistas, uno de los primeros fue Stéphane Mallarmée ya desde 1876, pero fue probablemente Émile Verhaeren quien, en artículos como «Exposición de Obras Impresionistas», mejor expresó este nuevo mundo de sensaciones vinculadas a una nueva teoría del color. Para él estos pintores lograban con su pintura toda la brillante y bella música de las notas altas y refiriéndose en particular a la obra de Renoir decía que su color alto, sonoro, cantante, hacía soñar con el creado por el gran genio de Delacroix «de donde surge igualmente la triunfante música de los tonos que compone Monet».

Resulta indudable la estrecha relación que en sus inicios tuvieron el impresionismo literario y el impresionismo pictórico, inicios en los que tampoco hay que olvidar las aportaciones de los hermanos René Ghil (Traité du verbe, 1886 y Méthode à l'oeuvre ), 1891dedicaran la máxima atención a Degas, el impresionista más próximo a las orquestas, a la música y a la danza, ya desde fecha tan reciente como el 13 de febrero de 1874 cuando dedican unas líneas a «un pintor extraño, de nombre Degas» enamorado de lo moderno y del que destacan la explicación que da el propio artista de su pintura a partir de un modelo coreográfico por la imitación de los arabescos de las bailarinas al tiempo que les entusiasma verle «mezclar a la estética del maestro de danza, la estética del pintor, hablando del pastoso tierno de Velázquez y del silueteado de Mantegna» ${ }^{2}$.

\footnotetext{
${ }^{2}$ Respecto a la obra Correspondances de Baudelaire, resulta muy interesante la relación de este poeta con el místico Swedenborg cuya influencia condujo a poner de moda los conciertos de perfumes en la línea de las excentricidades del personaje des Esseintes. Dicha relación es meticulosamente estudiada por Anna Balakian en su obra El movimiento simbolista, Madrid, Ediciones Guadarrama, 1969 , pp. 25 y s.s.

El término «Impresionistas» aparecería en un artículo de Louis Leroy, «Exposition des Impressionnistes», aparecido en Le Charivari, 25 abril 1874. Sobre estos pintores escribieron interesantes artículos Stéphane Mallarmée («The impressionnistes and Édouard Manet», en The Art
} 
Aunque al principio la forma sinestésica más destacada era la audición coloreada y la valoración cromática de las diferentes vocales, pronto los artistas del modernismo convertirían el procedimiento en una sinfonía de brillantes aromas, en un embriagador festín de colores y sensaciones táctiles. Y en este sentido no hay duda alguna de que la obra de Huysmans A Rebours, (1884), marca un hito insuperable hasta el punto de convertir a su irrepetible personaje, Jean des Esseintes, en el símbolo por excelencia del «mal del siglo».

Unico descendiente de la decadente y endogámica familia Floressas des Esseintes, que durante generaciones habían casado sus hijos entre ellos, Jean es un ser solitario, con un sistema nervioso exacerbado, enervado por la estulticia humana, que sueña con una tebaida refinada y a quien oprime un inmenso aburrimiento. Para superar este estado de ánimo ensayará todo tipo de experiencias estimulantes de sus sentidos, y así, tratando de potenciar y destacar la vivacidad de los tintes y matices de un tornasolado tapiz oriental, recubrirá el caparazón de una tortuga con una capa de oro incrustada de exóticas piedras preciosas de extraños colores como crisoberilos, peridotos verdes, olivinos, ceniza azul, ojos de gato de Ceilán o turquesas de Occidente. Otras veces será el sentido del gusto el que se prestará a este muestrario de sinestesias que constituye A Rebours, como la colección de barriles de licor que des Esseintes atesora en el comedor de su mansión a la que llama su órgano de boca. El aristócrata, paladeando cada gota de licor, compondrá en su boca sinfonías interiores creando sensaciones similares a las que la música produce en el oído

«cada licor correspondía, según él, como sabor, al sonido de un instrumento. El curaçao seco, por ejemplo, al clarinete cuyo canto es agridulce y aterciopelado; el kummel al obóe cuyo timbre sonoro es nasal; la menta y el anís a la flauta, al mismo tiempo azucarada y picante, chillona y dulce; mientras que, para completar la orquesta, el kirsch tiene el sonido furioso de la trompeta; la ginebra y el whisky se apoderan del paladar con su estridente fragor de cornetines de pistón y de trombones, el aguardiente de marc fulmina con el ensordecedor estrépito de las tubas, en tanto que se desencadenan los truenos del

Monthly Review, Londres 30 septiembre 1876), J.K.Huysmans ( L'Exposition des Independants», L'Art Moderne, Paris, 1883) y Émile Verhaeren («Exposition d'oeuvres Impressionnistes», Le Journal de Bruxelles, 15 junio 1885).

Goncourt, Edmond et Jules de: Journal, París, Robert Laffont, 1989, T. II, pp. 569-570.

De ese deseo de provocar sensaciones en todos los sentidos incluso se hacía eco una revista cómica como Chiarivari que en su número de 26 de abril de 1877, publicaba un chiste en el que se veía a un buen burgués contemplando un cuadro impresionista junto a su autor. El espectador comentaba: ¡Pero estos son tonos de cadáveres! y el artista contestaba: Sí, desgraciadamente no puedo llegar al olor. 
címbalo y del tambor golpeados con toda la fuerza, en la piel de la boca, por el rakis de Chio y las resinas» ${ }^{3}$.

Max Nordau, en su obra Degeneración en la que tan crítico se mostraba respecto a la obra de simbolistas y modernistas, considera al personaje de Huysmans como prototipo del decadente fin de siglo y nos lo presenta como el ideal baudelairiano, un enfermo débil mental, antinatural, con locura estética y diabolismo antisocial. Nordau, que se muestra catastrofista y profético, se refiere con escepticismo a las necesidades estéticas de la sociedad elegante que busca satisfacciones desconocidas y critica las exhibiciones en las que diferentes artes se esfuerzan por obrar simultáneamente sobre todos los sentidos por medio de combinaciones nuevas, tomándose a broma estos supuestos deleites estéticos: «en el teatro instalan un vaporizador que lanza perfumes sobre los espectadores; en la escena, un actor declama una poesía de forma aproximadamente dramática; en cada estancia, cada acto, cada escena, cualquiera que sea el nombre que se quiera dar a la cosa, domina una vocal distinta; en cada una de aquellas el teatro está alumbrado por una luz diferente; en cada una, la orquesta toca un trozo de ditinta factura y el vaporizador envía otro perfume diferente» ${ }^{4}$.

${ }^{3}$ Vid.Huysmans, J.K: A Rebours, 2a ed., Ed.Gallimard, 1977, p. 134.

En esta misma obra hay otros momentos realmente originales por lo que se refiere al uso y la creación de sinestesias. Por ejemplo, unos caramelos violetas llamados «Perlas de los Pirineos»e inventados por Siraudin, «eran una gota de perfume de sarcanthus, una gota de esencia femenina, cristalizada en un terrón de azúcar; penetraban en las papilas de la boca, evocaban recuerdos de agua opalizada por raros vinagres, de besos muy profundos, impregnados de olores»; a su vez, el sabor de estos caramelos le traía a la memoria el recuerdo de sus antiguas amantes: «En cabeza del desfile de enamoradas que el sabor de este caramelo ayudaba a dibujar con trazos ciertos, una se detuvo, mostrando unos dientes largos y blancos, una piel satinada, rosa, una nariz tallada en bisel, unos ojos de ratón, unos cabellos cortados a la chien y rubios».(Ibid. p. 205).

En otro lugar es el arte de los perfumes lo que tienta los ensueños vaporosos de des Esseintes que encuentra el placer de comparar la magia de los aromas con la de las ondas sonoras o la de los colores en la retina del ojo. «Poco a poco, los arcanos de este arte, el más descuidado de todos, se habían abierto a des Esseintes que descifraba ahora esta lengua, variada, tan insinuante como la literatura, este estilo de una concisión inaudita, bajo su apariencia flotante y vaga. Para ello, le fue al principio necesario trabajar la gramática, comprender la sintaxis de los olores, penetrar las reglas que les rigen, y, una vez familiarizado con este dialecto, comparar las obras de los maestros, de los Atkinson y de los Lubin, de los Chardin y de los Violet, de los Legrand y de los Piesse [...]. Con sus vaporizadores, inyectó en la habitación una esencia formada de ambrosía, de lavanda de Mitcham, de guisantes de olor, de bouquet, una esencia que, cuando es destilada por un artista merece el nombre que se le otorga de extracto de prado florido...». (Ibid.p.p.216 a 223).

${ }^{4}$ Vid. Nordau, Max: Degeneración, Madrid, Librería de Fernando Fé, T. I, p. 26. 
En cualquier caso no parece que los escritores modernistas en lengua castellana fueran muy proclives a este tipo de experiencias en las que se mezclaban aromas, colores y sabores. Por el contrario, las sinestesias en las que se implicaban poesía, música y color fueron frecuentísimas en sus obras.

José Martí, que estuvo en París a finales de 1874, recibió probablemente la influencia de los impresionistas como podría evidenciar esta descripción de un paisaje de Orizaba, en Méjico, recogida por Iván Schulman: «circundaban las nubes crestas rojas y se mecían como ópalos movibles; había en el cielo esmeraldas vastísimas azules, montes turquinos, rosados carmíneos, arranques bruscos de plata, desborde de los senos de color; sobre montes oscuros, cielos claros, y sobre cuestas tapizadas de violetas, arrebatadas ráfagas de oro».

Pero lo que es seguro es que el poeta cubano conocía el soneto Voyelles de Rimbaud y concebía el arte en términos sinestésicos lo cual confirma este pasaje escrito en 1881

«Entre los colores y los sonidos hay una gran relación. El cornetín de pistón produce sonidos amarillos; la flauta suele tener sonidos azules y anaranjados; el fagot y el violín dan sonidos de color castaño y azul Prusia, y el silencio, que es la ausencia de los sonidos, el color negro. El blanco lo produce el oboe».

Muy pronto, apoyándose no solo en la influencia de los poetas y pintores franceses sino también en la experiencia becqueriana, aparecerá en él la pasión por utilizar para sus logros artísticos la fusión de la luz, el color y los sonidos mezclando con el sonido del arpa la luz de oro y los hermosos colores del seno de las nubes, especialmente el azul y el oro, y ya en 1876 explicitará sus sentimientos con estas palabras: «Poetas, músicos y pintores, son esencia igual en formas distintas; es su tarea traer a la tierra las armonías que vagan en el espacio de los cielos, y las concepciones impalpables que se agitan en los espacios del espíritu». Para él, el sonido tiene más variantes que el color y este a su vez más que la palabra y en consecuencia la belleza será más fácil de expresar a través de la música que de la pintura y esta será también más bella que la poesía porque al ser la belleza la conformidad del espíritu con lo vago, lo exquisito y lo indescifrable, se expresará mejor en tanto que encuentre mayor extensión para manifestarse. Es por ello que en algún momento afirmó «Lo verdadero es lo que no termina: y la música está perpetuamente palpitando en el espacio» ${ }^{5}$.

${ }^{5}$ Cfr. Schulman, Iván A.: Génesis del Modernismo, El Colegio de México/Washington University Press, 1966, pp. 37 a 39-59.

El Simbolismo, op. cit. en la nota 1, p. 250. 
Estos años entre 1874 y 1876 fueron fundamentales para la cristalización del movimiento modernista y muy especialmente desde el punto de vista de la concreción de este sistema basado en las sinestesias. Es también en 1876 cuando Gutiérrez Nájera publica en El Correo Germánico de Méjico su amplio artículo por entregas «El arte y el materialismo». En la última de ellas, con fecha 5 de septiembre, Nájera nos habla, como Martí, de las múltiples manifestaciones de un solo principio que es el arte, principio que se eleva fascinante y luminoso frente al negro fantasma del materialismo, que en la música ve encarnado en la mefítica atmósfera del can-can parisino y las composiciones de Offenbach, y que tiene su expresión en todo lo que es bello, desde las idealistas obras de Calderón de la Barca hasta las tiernas quejas de la música de Bellini, desde las copas venecianas hasta los tapices de vivos colores.

También en Juan Ramón Jiménez el color tiene un fuerte contenido simbólico, si bien el carácter sinestésico no aparece con tanta frecuencia como en otros poetas del ámbito hispanoamericano. Casi siempre el color de sus poesías aparece ligado a sentimientos o a imágenes visuales pero en pocas ocasiones lo veremos vinculado a sonidos, armonías y mucho menos a olores o impresiones táctiles. No hay que olvidar que el poeta quiso ser pintor y en realidad no dejó de serlo nunca y es por ello que el color se convierte en una constante en toda su literatura, especialmente en su primera época, hasta el punto de que las palabras parecen ser utilizadas en sus textos como los colores en los cuadros de un pintor impresionista constituyendo la luz un elemento fundamental en su prosa hasta el punto de que llegaría a decir «escribir, para mí, es dibujar, pintar; me sería imposible escribir en la oscuridad». y no es difícil aceptar la sinceridad del poeta en esta afirmación ante la lectura del poema «Mar de pintor», incluído en su Diario

«Cuatro de la madrugada: Mar azul Prusia.

Cielo verde de malaquita. Emociones.

Seis de la mañana: Mar morado. Cielo gris. Sports.

Nueve de la mañana. Lectura.

Una de la tarde: Mar ocre. Cielo blanco. Desamor.

Cuatro de la tarde: Mar de plata. Cielo rosa. Nostaljia.

Ocho de la tarde: Mar de hierro. Cielo gris. Pensamientos.»

En el escritor de Moguer el paisaje es color y el color es poesía. Rojos son sus Jardines galantes, blancos sus Jardines místicos, dorados y malvas sus Jardines dolientes. Por el contrario, la música no constituye un elemento de importancia en su obra y tan solo alcanza a evocar lo musical en algunas alusiones a los instrumentos que la producen, incluyendo incluso en alguna ocasión partituras musicales como introducción de sus libros de poemas, o en algunos 
efectos verbales de sus poesías, pero sin que llegue a constituir la sonoridad melódica un argumento operativo en su producción literaria ${ }^{6}$.

No es este el caso de Rubén Darío para quien la música es el más puro exponente del Arte, que es a su vez su religión. Es el lugar de los misterios, donde se funden de forma enigmática lo místico, lo mágico y lo erótico, discurriendo el ritmo de la vida entre el silencio y los sonidos armónicos. El poeta nicaragüense sintetizará este sentimiento en el mito de Pan, el lúbrico dios que asume en un solo ser la vitalidad animal del macho cabrío y la divinidad que implica el conocimiento de la música y que hace a los hombres como dioses.
«Y luego Pan, con la armoniosa flauta, la dulce flauta de oro;
y un universo en gigantesca pauta,
a su melífluo son formando coro».

En Darío, la métrica del verso aparece íntimamente vinculada a la musicalidad y su experimentación en este campo lo demuestra, lo cual no deja de constituir una especial forma de sinestesia visual y sonora. El poeta explicita esta circunstancia al hablarnos de su obra Cantos de Vida y Esperanza en estos términos: «Elegí el hexámetro por ser de tradición greco-latina y porque yo creo, después de haber estudiado el asunto, que en nuestro idioma, malgré la opinión de tantos catedráticos, hay sílabas largas y breves, y que lo que ha faltado es un análisis más hondo y musical de nuestra prosodia [...]. Flexibilizado nuestro alejandrino, con la aplicación de los aportes que al francés trajeran Hugo, Banville y luego Verlaine y los simbolistas, su cultivo se propagó, quizá en demasía, en España y América».

Son igualmente innumerables los ejemplos de sinestesias y metáforas cromáticas en Rubén Darío que nos habla de risas de plata, rojos destinos, versos azules, y que en ocasiones funde con la música para construir una poesía como

' Sobre el tema del color en la obra de Juan Ramón Jiménez son muy interesantes las obras de Crespo, Angel: Juan Ramón Jiménez y la pintura, Puerto Rico, Editorial Universitaria, 1974 y González, Angel: Juan Ramón Jiménez, Madrid, 1974.

También conviene recordar la obra de Lily Litvak Erotismo fin de siglo, Antoni Bosch, editor, Barcelona, 1979, en la que la autora analiza la obra de tres autores, Juan Ramón Jiménez, Valle-Inclán y Felipe Trigo. Para ella «algunos colores juanramonianos invitan a un erotismo violento, otros al ensueño y a la contemplación, otros a la melancolía y al pesimismo. Si unos tonos son apasionados y ardientes, otros son calmos y tristes, otros llorosos, terribles o trágicos. El rojo y la gama de matices y colores relacionados con él, representan sensaciones de placer, de sensualidad. El violeta le habla del pasado. Es sensible a los tonos satinados de la luna. Se encuentran manchas grises que expresan la fatiga de los sentidos. El negro evoca el peligro del abismo.» Op. cit. p. 29. 
por ejemplo en el soneto $E l$ Cisne para el que fue iniciado en los secretos wagnerianos por el músico y escritor belga Charles du Gouffre con este resultado
$\ll_{i} \mathrm{Oh}, \mathrm{Cisne!} \mathrm{¡Oh,} \mathrm{sacro} \mathrm{pájaro!} \mathrm{Si} \mathrm{antes} \mathrm{la} \mathrm{blanca} \mathrm{Helena}$
del huevo azul de Leda brotó de gracia llena, siendo de la hermosura la princesa inmortal, bajo tus blancas alas la nueva Poesía concibe en una gloria de luz y de armonía la Helena eterna y pura que encarna el ideal» ${ }^{\text {? }}$.

Otro de los escritores modernistas que practicaron con asiduidad el recurso estético de las sinestesias fue Herrera y Reissig, el poeta uruguayo de la torre de marfil, que compondrá un capricho lírico con un título tan sinestésicamente sugerente como «Solo amarillo para flauta. Clave de U». Pero es tal vez en su colección de sonetos Las clepsidras, subtitulado intencionadamente «Cromos exóti$\cos »$, donde el poeta lleva a sus últimas consecuencias este universo en el que se funden los sonidos, los componentes cromáticos, los brillos y las sombras, la musicalidad de la palabra y la vibración de un atardecer, con el interés añadido de un orientalismo que como veremos estaba en la raiz del mundo de las sinestesias desarrollado por los precursores parnasianos y simbolistas franceses.

También Ramón del Valle-Inclán, al publicar en 1902 Corte de amor, dedicará a las sinestesias un lugar destacado para hacer profesión de su fe modernista. Considera Don Ramón que una característica fundamental del modernismo es un vivo anhelo de personalidad debido a lo cual estos escritores ponen mayor empeño en expresar sensaciones que ideas ya que en su opinión, las ideas nunca han sido patrimonio exclusivo de un solo hombre y las sensaciones sí, lo cual le lleva a afirmar

${ }^{7}$ Los versos dedicados a Pan aparecen en Darío, Rubén: Poesías completas, «Epístolas y poemas» 9a ed., Madrid, Aguilar, 1961, p.428. En El simbolismo, nota 1, se incluye un trabajo de Jaime Giordano en el que se ocupa del simbolismo de Rubén Darío a travès de la música y del misterio, pp. 126 a 134.

También resulta muy interesante respecto a las relaciones de Rubén Darío con la música la obra de Erika Lorenz: Rubén Dario, «bajo el divino imperio de la música», Managua, Ediciones Lengua, 1960.

Vid. Darío, Rubén: «Cantos de Vida y Esperanza» en Historia de mis libros, Obras Completas, Vol.XVII, Madrid, ed.Mundo Latino, 1919, p.206.

Sobre el tema de la métrica modernista ver Henríquez Urueña, Max: Breve historia del Modernismo, Fondo de Cultura Económica, $2^{a}$ edición, 1962, p.p. 14 a 16: Férnández Molina, Antonio: Antología de la poesía modernista, Madrid, Ed.Júcar, 1981, p.p.31 y s.s.

Darío se refiere al soneto «El Cisne» en Historia de mis libros, Op.cit. en esta nota, p.193. 
«La condición característica de todo el arte moderno, y muy particularmente de la literatura, es una tendencia a refinar las sensaciones y acrecentarlas en el número y en la intensidad.»

Influido por los simbolistas franceses, Valle-Inclán recuerda en este conocido texto como Baudelaire gozaba con las sinfonías de perfumes o como Carducci había llamado verde al silencio y se hace eco de una teoría muy en voga en aquellos años en Francia desarrollada por el profesor de la Universidad de Breslau Hugo Magnus en su obra Histoire de l'évolution du sens des couleurs según la cual el hombre a lo largo de su historia habría seguido un proceso de identificación progresiva de las sensaciones coloreadas y de un posterior refinamiento de dicha diferenciación cuyo proceso final se estaría alcanzando con los artistas de la modernidad.

Sin duda para Valle-Inclán las cosas más bellas creadas por los hombres son para los ojos y los oídos e incluso la esencia que expresan las letras pertenece a la música. Por otro lado, es el único autor que considera el baile como la más alta expresión estética porque en él se funden los sutiles caminos de la belleza, la luz y el sonido, transportando a los ojos los números y los ritmos musicales. «Los ojos y los oídos se juntan en un mismo goce, y el camino craso de los números musicales se sutiliza en el éter de la luz» ${ }^{8}$.

Tampoco los modernistas catalanes fueron ajenos al procedimiento de las sinestesias. Así, Ramón Casellas destacaría en este sentido la figura de Whistler, pintor que había hecho música de la pintura como sostiene Guy Michaud: «Músico también él, que compone Sinfonías en verde y violeta, en blanco y rojo, en azul y rosa, toma de Chopin el título de sus Nocturnos, e intenta crear a través del color una equivalencia de las emociones musicales» ${ }^{9}$. Otros autores como Alexandre Cortada y Jaume Brossa se ocuparon desde las páginas de L Avenç de estas cuestiones especialmente a través del debate entre los postulados de los primeros modernistas catalanes vinculados a los planteamientos naturalistas de

'Vid.Valle-Inclán, R.: La Ilustración Española y Americana, 22 febrero 1902. Posteriormente incluiría este texto en el volumen Corte de amor de 1903, que no era sino una reimpresión de su primer libro Femeninas. Recogido en Henríquez Urueña, Max: Breve historia del Modernismo, Méjico, Fondo de Cultura Económica, 1962, p. 168.

Émile Verhaeren se ocupa de esta cuestión del refinamiento progresivo de las sensaciones por parte del hombre a lo largo de la Historia en su artículo citado en la nota 2. Cfr.Riout, Denis (Selección de textos): Les écrivains devant l'impressionnisme, Paris, Ed. Macula, 1989, p. 362.

Vid.Valle-Inclán, R.: La lámpara maravillosa, Madrid, Espasa-Calpe, $3^{\mathrm{a} e d i c i o ́ n, ~ p . ~} 54$.

'Vid.Michaud, Guy: Message poétique du Symbolisme, París, Nizet, 1947, pp. 256 a 258. 
Emile Zola, que había representado la modernidad, y la nueva estética simbolista que parecía a muchos una vuelta al pasado.

Para terminar recojamos un ejemplo de color, más simbolista que modernista, en la obra de un hombre del 98, el Unamuno de El Cristo de Velázquez donde se mezclan el arte pictórico, la estética y la religión a través del método dialéctico.

La tesis de la obra es el Dios dador de inmortalidad. La antítesis la humanidad contaminada por el pecado, corrupta y condenada a la muerte, la muerte misma simbolizada por el Cristo de Santa Clara. La síntesis el Hombre-Dios, el mito en el que la Humanidad cumple su destino inmortal. El Cristo de Velázquez.

En esta oración en verso, decir color es decir simbolismo. Es lo primero que se debe señalar; el poema de Unamuno es un poema en color, pero un color austero, un claroscuro, un poema maniqueo en blanco y negro, como el cuadro de Velázquez. Resulta evidente que nada en la pintura del sevillano, vista a la luz de un cuadro religioso de la escuela española del siglo XVII, invita a hablar de simbolismo; sin embargo interpretada por el sueño unamuniano, todo se convierte en simbólico.

Dice Jeschke-que no cita a Unamuno-que los colores favoritos para el modo impresionista de ver de los escritores noventayochistas, son, en primer lugar, el blanco y luego el negro y el amarillo ${ }^{10}$. En este poema, encontramos una confirmación absoluta de la investigación de Jeschke, con la sustancial diferencia de que el modo impresionista de ver se troca aquí en visión simbolista, evocadora y mística.

Aparte del blanco y el negro, los únicos colores que aparecen en el poema son el rojo de la sangre de Cristo y del vino de Caná, el azul de sus ojos del color del cielo, y el amarillo caballo de la muerte. El resto es una sinfonía en la que se suceden en armónica alternancia, oponiéndose y complementándose pero nunca fundiéndose los dos colores que son la suma de todos y su negación total.

Blanco es ante todo el cuerpo de Cristo, con la blancura de la luna, blanco el vuelo de la paloma, el Águila símbolo del alma, los lirios del corazón, la eternidad; blanca incluso la Muerte vencedora de la muerte.

Por el contrario es negro el cielo de la noche soberana, la abundosa cabellera de nazareno, el abismo de Dios en el que se emboza el Cristo, la sombra

${ }^{10}$ Jechske, Hans: La generación de 1898, Madrid, 1954, p. 123. 
del ala de Luzbel, la melena del Blanco León de los desiertos, el manto de la muerte.

El color blanco del cuerpo de Cristo no es sino el reflejo de la luz divina, de ese Dios eterno e inmortalizador que el hombre anhela, y por eso compara su blancura con la de la luna que refleja como un espejo la luz del sol. Este símbolo de la blanca luna, que tiene mucho que ver con las ideas de Platón, confirma, con su serena belleza, que Unamuno veía en él la revelación de la existencia de Dios y el triunfo de la Humanidad sobre la muerte.

El color negro hace referencia a la melena del Nazareno y a la noche, y está sin duda inspirado por el fondo de tinieblas del cuadro. Simboliza la oscuridad en la que vivía el hombre sin el conocimiento de Dios antes de la venida de Cristo, la angustia de la nada negadora. Pero también representa, por oposición a la luz de Cristo, las fuerzas tenebrosas, el ángel caído, Luzbel ${ }^{1 i}$.

\footnotetext{
"Unamuno:El Cristo de Veläzquez, Madrid, Espasa Calpe, 1984 pp. 17 y 22.

«Blanco tu cuerpo está como el espejo

del padre de la luz, del sol vivífico;

blanco tu cuerpo al modo de la luna [...]

De noche la redonda luna dícenos

de como alienta el sol bajo la tierra:

y así tu luz: pues eres testimonio

Tú el único Dios, y en esta noche

sólo por Tì se llega al Padre Eterno:

sólo tu luz lunar en nuestra noche

cuenta que vive el sol».

Ibid. p.p. 24 y 44 .

"con tus abiertos brazos, la negrura

del abismo de Dios, tu Padre, rasgas

y echándolo hacia atrás, de tu cruz cuelgas

el negro manto en que embozado estabas

dándotenos desnudo [...]

$¿ O$ es que una nube negra de los cielos

ese negror, le dio a tu cabellera

de nazareno, cual de mustio sauce

de una noche sin luna sobre el río?

¿Es la sombra del ala sin perfiles

del ángel de la nada negadora,

de Luzbel, que en su caída inacabable

-fondo no puede dar- su eterna cuita

clava en tu frente, en tu razón?.
} 


\section{LA ESTÉTICA AZUL}

En pocas ocasiones se ha visto un movimiento artístico tan vinculado, tan «teñido» por un color como en el caso que ahora nos ocupa. Pero ¿por qué es azul el modernismo?.

Son suficientemente conocidas las dos cartas que dedicó Juan Varela al libro que con este título le remitió Rubén Darío desde América. El escritor español, que dedicó elogiosos comentarios al mismo, reconocería que sin embargo en un primer momento lo había recibido con indiferencia debido precisamente a su título: Azul. Recordaba don Juan que ya Victor Hugo había dicho «L'art c'est l'azur», con lo cual venía a acusar a Darío de falta de originalidad además de no compartir esta opinión porque para él «tanto vale decir que el arte es lo azul, como decir que es lo verde, lo amarillo o lo rojo. ¿Por qué, en este caso, lo azul (aunque en francés no sea bleu sino azur, que es más poético) ha de ser cifra, símbolo y superior predicamento que abarque lo ideal, lo etéreo, lo infinito, la serenidad del cielo sin nubes, la luz difusa, la amplitud vaga y sin límites, donde nacen, viven, brillan y se mueven los astros?». Añadía finalmente que no veía en la afirmación de Hugo más que una frase enfática y vacía ${ }^{12}$.

Algo más tarde el poeta nicaragüense vendría a matizar las opiniones de Varela en Historia de mis libros donde, además de asumir como fundamento de su renovador estilo el conocimiento de los autores franceses del Parnaso y a Catulle Mendès como su auténtico iniciador, reconocía haber explorado «la inmensa selva de Víctor Hugo» pero negaba conocer en la época de la publicación de su obra Azul la citada frase de Hugo «L'art c'est l'azur» aunque sí una canción del mismo poeta en Les Châtiments donde decía «Adieu, patrie! L'onde est en furie. Adieu, patrie, azur!.» Es también en este trabajo donde explica Rubén sus estímulos poéticos ante este color

«Mas el azul era para mí el color del ensueño, el color del arte, un color helénico y homérico, color oceánico y firmamental, el «coeruleum», que en Plinio es el color simple que semeja al de los cielos y al zafiro»

Es por ello que concentraría en ese color del cielo lo que el poeta llamaba «la floración espiritual de mi primavera artística» ${ }^{13}$.

${ }^{12}$ Cfr. Varela, J.: Cartas Americanas, 22 octubre 1888, recogidas en Darío, R.: Azul, Obras Completas, Vol.IV, Madrid, Mundo Latino, pp. V-VI.

${ }^{13}$ Cfr.Darío, R.: Historia de mis libros, Obras Completas, Vol.XVII, Madrid, Mundo Latino, 1919 , pp. 170 a 172. 
No se entiende sin embargo la afirmación de Darío de que desconocía la citada frase de Victor Hugo sobre la esencia azul del arte si se tiene en cuenta el estudio realizado por Raúl Silva Castro sobre esta cuestión. Recuerda este escritor que con ocasión de la publicación de la segunda edición de Azul en 1890 Rubén Darío había hecho unos comentarios sobre «esta frase de Víctor Hugo que sirve de epígrafe al prólogo de don Eduardo de la Barra». Se refiere efectivamente al prólogo que este escritor chileno había añadido a su edición de 1888 en cuyo encabezamiento se podía leer: "L'art c'est l'azur. Victor Hugo» añadiendo además de la Barra algunas precisiones sobre el azul de su propia pluma. «Sí, el arte es el azul, pero aquel azul de arriba que desprende un rayo de amor para encender los corazones y ennoblecer el pensamiento y engendrar las acciones grandes y generosas». Todo ello anularía de forma definitiva la presunción de desconocimiento de la frase huguesca por parte de Rubén Darío, lo cual por otro lado no representa ningún desdoro para la creatividad poética del nicaragüense ${ }^{14}$.

De lo que no puede quedar ninguna duda es de la enorme influencia de la poesía francesa en su obra. El primero en señalarlo es el propio Valera en las cartas que acabamos de comentar en las que su autor confiesa que hay tanto de francés en las exquisiteces del pensamiento de Darío que le resultaba imposible comprender como, sin haber estado inmerso en el medio ambiente parisino había sido capaz de asimilar tan íntimamente todos los elementos del espíritu de Francia, viendo en él la influencia entre otros de Baudelaire, Leconte de Lisle, Gautier, Daudet, Zola, Catulle Mendès, Goncourt o Flaubert. Pero es el propio Darío el que reconoce orgulloso el origen de su éxito y el aplauso de sus compañeros de letras en su reciente descubrimiento de los autores franceses parnasianos y de la lucha simbolista, presentando a Catulle Mendès como su verdadero iniciador al que seguirían otros como Gautier, Flaubert o Paul de Saint Victor, sin olvidar que su penetración en el mundo verbal francés había empezado en San Salvador explorando la obra inmensa de Victor Hugo ${ }^{15}$.

Para los simbolistas franceses toda palabra no tenía otro valor que el del misterio que ayudaba a presentir, asignando a la poesía una tarea metafísica o mística suprema, la revelación de la Verdad. El precursor habría sido Baudelaire, descubridor de las misteriosas correspondances que existían primero entre nuestras sensaciones y luego entre nuestras sensaciones y el mundo espiritual de tal forma que el mundo real nos es evidenciado por dichas sensaciones que no son

${ }^{14}$ Vid. Silva Castro, Raúl: El ciclo de lo «azul» en Rubén Darío. Recogido en Estudios críticos sobre el Modernismo, edición de Homero Castillo, Madrid, Editorial Gredos, 1968.

${ }^{15}$ Cfr. Darío, R.: Op.cit. en las notas 12, p.p.VIIIa XI y 13, p. 170. 
sino el símbolo de esta realidad. Será precisamente Baudelaire en su poesía Correspondances quien nos hablará de los perfumes, colores y sonidos que se responden «igual que largos ecos lejanos, confundidos en una tenebrosa y profunda unidad, vasta como la noche y cual la claridad». Siguiendo estos planteamientos Rimbaud se dedicaría a partir de 1871 a la composición de ejercicios de alquimia verbal como son por ejemplo sus versos del «Soneto de las vocales» en los que hace coresponder al sonido de cada una de las vocales un color: «A noir, E blanc, I rouge, $U$ vert, $O$ bleu, voyelles...». Su procedimiento será ampliado y modificado por René Ghil que unirá el sonido de las vocales con los colores y con el registro de los instrumentos musicales haciendo corresponder al órgano la vocal A y el color negro de las tinieblas, al arpa la $\mathrm{E}$ y el color blanco, a los violines, registro de la pasión, la I y el color azul, a los metales la $\mathrm{O}$ y el color rojo de los sonidos triunfales y finalmente a la flauta la $\mathrm{U}$ y el dinámico color amarillo.

Estos experimentos influyeron sin duda en los poetas de habla hispana como ya hemos visto en José Martí que en 1881 escribía aquello de

«El cornetín de pistón produce sonidos amarillos; la flauta suele tener sonidos azules y anaranjados...etc».

Pero entre todos será el azul el color mágico, el más simbólico, el más evocador y el más querido por estos poetas.

Ya Alfred de Vigny, como nos recuerda Théophile Gautier, en su poema de 1823 «Eloa» habla de los ojos azules del ángel Eloa que allá en la bóveda azul lleva un velo azul como más tarde llevará la reina Mab en la poesía de Rubén Darío. El propio Gautier en su Emaux et Camées de 1852 utilizará con frecuencia como recurso poético los términos bleu y azur usados en general como adjetivación de este color el primero y como evocación de aspectos simbólicos vinculados al azul del cielo y del agua el segundo. Pero probablemente sea Charles Baudelaire, que dedicó varios de sus poemas como homenaje a Victor Hugo, quien dará al color azul la mayor parte de los contenidos simbólicos que posteriormente le conferirían los poetas modernistas. Casi siempre unido a la imagen del cielo y del mar, Baudelaire nos hablará de «la incomparable castidad del azul» como símbolo del lugar donde reinan la pureza y el ideal o asimilará su espíritu moviéndose libremente con un buen nadador surcando la azul inmensidad. El poeta invita a su musa a ir al lugar de la inspiración, a recoger «el oro de la bóveda azul», mientras que en otros momentos es el lugar de la vida interior: «Allí he vivido yo en venturosas calmas, en medio del azul, de oleajes, de esplendores». Pero el azul es también el lugar donde tiene su trono la belleza, esfinge incom- 
prendida, o el cielo inaccesible para el hombre caído. Y siempre el lugar ideal, el lugar de la ensoñación y de la virginidad original

Dime, ¿tu corazón, Ágata, a veces huye lejos del negro océano de la inmunda ciudad en busca de otro mar que centellea y fluye azul, claro, profundo cual la virginidad? Dime, ¿tu corazón, Ágata, a veces huye?

También para Stéphane Mallarmé es el azul un elemento simbólico y carismático. En su poema «L'Azur» exclamará

«...el Azul triunfa, y yo lo oigo cantar en las campanas...

Estoy obsesionado. L'Azur! 1'Azur! L'Azur! L'Azur! ${ }^{16}$.

En cualquier caso, no puede extrañar esta valoración del azul como un elemento poético de primera magnitud entre los escritores franceses en una época en la que el ascenso del irracionalismo y del pensamiento análogico, es decir del simbolismo, conducían a una revitalización de los estudios sobre el mundo medieval así como a un sentimiento de curiosidad por civilizaciones exóticas o desaparecidas como reacción frente al clasicismo, el positivismo y la racionalidad. Esta reivindicación del sentido de misterio llevaría a su vez a un renacimiento del orientalismo como postularía Quinet en su libro de 1841 Le Génie des Religions y a partir de este momento el mazdeismo, el hinduismo, el budismo o el Islam se convertirían en fecundo manantial de inspiración para los románticos y más tarde para los simbolistas.

En esta línea se encontrarían obras como Des Couleurs Symboliques de Fréderic Portal publicada en 1839 en la cual el autor analizaba el lenguaje de los colores en su íntima relación con las antiguas religiones de la India, China, Egipto, Persia o Grecia y que tendría su continuación en las vidrieras de las catedrales góticas. En su libro recordaba Portal, basándose en la Biblia, que el aire así

${ }^{16}$ Baudelaire, Ch.: «Correspondencias», Las flores del mal, Madrid, EDAF, 1985, pp. 34 a 36.

Martí, José: Sección constante, ed. Pedro Grases, Caracas, Imprenta Nacional, 1955, p. 26.

Alfred de Vigny y Téophile Gautier, citado por Boyd G.Carter en : La «Revista Azul». La resurrección fallida: Revista Azul de Manuel Caballero en El Modernismo, edición de Lily Litvak, Madrid, Taurus Ediciones, 1975, pp. 340 a 342.

Baudelaire, Ch.: «Elevación», «La musa pobre», «La vida interior», «La belleza», El alba espiritual», «Moesta et errabunda», Op.cit. en esta nota, pp. 32-41-45-52-96-124.

Mallarmée, Stéphane: L'Azur. Publicado en Le Pamasse contemporaine en 1866. 
como su color el azul celeste es el símbolo del Espíritu, pero además destacaba el hecho de que en las antiguas cosmogonías el Dios creador es siempre del color azul del cielo como símbolo de la sabiduría divina creadora del mundo. Así, Vishnú aparece siempre de este color del cual habría nacido e igualmente azul es Krishna en quien encarna la sabiduría divina para salvar a los hombres. También el azul es el color de Júpiter, el de Amón, el dios-carnero de Egipto, siendo el cielo azul el dios supremo de la China. En definitiva venía a decir este autor que el azul representaba la verdad eterna, la inmortalidad y la fidelidad ${ }^{17}$.

Hecha esta somera aproximación al descubrimiento del azul como elemento simbólico por parte de los poetas franceses, volvamos a Rubén Darío y a su sentido del azul aunque como enseguida veremos no toda la crítica ve en el nicaragüense el introductor de este recurso poético en las letras hispanoamericanas.

Ya desde antes de la publicación de $A z u l$, en particular desde su estancia chilena en 1886, Darío va utilizar este color no sólo como imagen de lo celeste, sino como símbolo del ideal y de la inspiración. El 7 de diciembre de 1886 publicaba en La Epoca de Santiago de Chile su cuento «El pájaro azul» en el cual aparece un neurótico poeta llamado Garcín en cuyo cerebro anida, según él mismo cree, un pájaro azul que tan sólo quedará liberado cuando el poeta se quite la vida. «Hoy, en plena primavera, dejo abierta la puerta de la jaula al pobre pájaro azul». El ave, que no es otra cosa que el ensueño y la inspiración, abandonará las tristes moradas terrenales para volar hacia el cielo azul, hacia la región empírea de la belleza y del ideal. A partir de este momento los ejemplos se van a multiplicar y así el poeta exclamará «iPrincesa del divino imperio azul, quién besará tus labios luminosos!», nos hablará en «El palacio del sol» de la princesa de un cuento azul, verá en «El ideal» un rostro de mujer como un sueño azul, y adorará en «Anagke» la niebla sutil de polvos de oro del inmenso azul.

Pero será sobre todo en su cuento «El velo de la reina Mab», publicado en La Epoca el 2 de octubre de 1887 donde Rubén Darío va a exponer de forma más explícita lo que quería evocar con su azul. Describe allí como Mab, la reina de las hadas, entraba sobre un rayo de sol por la ventana de una buhardilla para encontrar a cuatro hombres, barbudos y flacos, quejándose amargamente de los dones

${ }^{17}$ Vid. Portal, Fréderic: El simbolismo de los colores, Palma de Mallorca, Ediciones de la Tradición Unánime, 1989, p.p.71 a 81.

También José Martí se refirió en alguna ocasión al simbolismo cromático azul para representar la virtud. «...el símbolo búdico del bien y del mal, que es uno como círculo doble, a manera de letra se (sic), con el hemisferio del mediodía rojo, como el mal, y el del norte azul como la virtud».Vid. Schulmann, Iván A.: Símbolo y color en la obra de José Martí, Madrid, Editorial Gredos, 1960, p. 472. 
que les habían repartido las hadas, una cantera, el iris, el ritmo y el cielo azul, es decir que se trataba de un escultor, de un pintor, de un músico y de un poeta. Su queja se debía a que pesar de estos dones el desaliento les atenazaba por la incomprensión de los hombres que sintetizaba el poeta con estas palabras: «Yo escribría algo inmortal; mas me abruma un porvenir de miseria y hambre».

«Entonces la reina Mab, del fondo de su carro hecho de una sola perla, tomó un velo azul, casi impalpable, como formado de suspiros o de miradas de ángeles rubios y pensativos. Y aquel velo era el velo de los sueños, de los dulces sueños que hacen ver la vida de color đe rosa. Y con él envolvió a los cuatro hombres flacos, barbudos e impertinentes [...]. Y desde entonces, en las buhardillas de los brillantes infelices, donde flota el sueño azul, se piensa en el porvenir como en la aurora, y se oyen risas que quitan la tristeza, y se bailan extrañas farándulas alrededor de un blanco Apolo, de un lindo paisaje, de un violín viejo, de un amarillento manuscrito».

Recordemos finalmente un artículo publicado en La Tribuna de Buenos Aires con el seudónimo Des Esseintes y recogido por Raúl Silva Castro que pone a Rubén Darío en relación con «L'Azur» de Mallarmé

«Bendito sea aquel que siempre anuncia la aurora.

¿Acaso porque sufres tienes derecho a emponzoñar el mundo con tus dolores? Escritores, el primer deber es dar a la humanidad todo el azul posible.

Guerra a lo negro.

¡Azul! ¡Azul! ‘Azul!» ${ }^{18}$.

Ahora bien, como decíamos al principio de este apartado, no toda la crítica está de acuerdo en que fuese Darío el primero en descubrir el poder evocador del azul y su capacidad de seducción estética en el contexto de las letras hispánicas. De hecho, para Iván A. Schulman es innegable que entre los iniciadores del modernismo corresponde a José Martí dicho descubrimiento y la incorporación del azul a su léxico como elemento estilístico. Recuerda el citado autor que ya desde 1875 , es decir desde su primer exilio en Méjico y once años antes que Dario, usa Martí este color como elemento simbólico refiriéndose a la lejanía del azul soñado o a su poder como evocación del exquisito espíritu de la persona amada, es decir con las mismas connotaciones de belleza, ideal y evasión de la realidad hacia el mundo de la poesía que ya hemos visto en el poeta nicaragüense.

${ }^{18}$ Darío, R.: «El pájaro azul», «Palacio del sol», «Ideal», «Anagke», «La reina Mab», Azul, Barcelona, Ediciones 29, 1990, pp. 48 a 52-43 a 47-71-105 a 107 y 20 a 30.

Vid. Silva Castro, Raúl: Op. Cit. en la nota 14, pp. 146 a 167. 
A partir de esta fecha vendrán «la religión vasta y azul», los inmaculados días azules, nuestros países azules, el azul soñado, el lago azul del amor o la tristeza azul como forma simbólica a través de la cual busca elevar la realidad objetiva hacia un estrato moral o artístico superior. Aún más explícito resulta Martí en su novela de 1885 Amistad funesta donde aparecen los «pájaros azules» como símbolo del anhelo juvenil de ilusión y libertad en un fragmento por cierto bastante misógino

«Estaban las tres amigas en aquella edad en que los caracteres todavía no se definen: jay! en esos mercados es donde suelen los jovenes generosos, que van en busca de pájaros azules, atar su vida a lindos vasos de carne que a poco tiempo, a los primeros calores fuertes de la vida enseñan la zorra astuta, la culebra venenosa, el gato frío e impasible que les mora en el alma» ${ }^{19}$.

Pero en general podemos decir que este color denota en la mayoría de los casos cualidades de idealización que adornan al ser superior, a aquel que es capaz de alcanzar y descubrir las moradas más elevadas de la espiritualidad, así como también sirve este símbolo cromático para expresar la alegría de vivir o la belleza suprema como cuando nos habla de música azul en un poema dedicado a la niña de Gutiérrez Nájera

«En la cuna sin par nació la airosa

Niña de honda mirada y paso leve,

Que el padre le tejió de milagrosa

Música azul y clavellín de nieve» ${ }^{20}$.

También Manuel Gutiérrez Nájera se vio involucrado en este juego de las sinestesias y del simbolismo del color desde una época temprana. Ya en su poema de 1876 «Luz y sombra» escribirá el poeta: «Es blanca tu conciencia y azul tu pensamiento». Y algo más tarde, en 1880 , escribirá Del libro azul. Sin embargo, no será hasta el 6 de mayo de 1894 cuando publicará la Revista Azul, cuyo programa incluía, como dice Boyd G.Carter «el ascenso hacia el azul, símbolo de la elevación desinteresada del espíritu, de la imaginación poética y de otros valores simbólicos». Es en esta revista donde el poeta y todos sus colaboradores desarrollaron una teoría del azul como símbolo cromático vinculado a los planteamientos de los escritores franceses, Gautier, Hugo y Baudelaire, en primer término. Pero como señalábamos, ya desde casi dos décadas antes se había sentido

19 Vid.Schulmann, Iván A.: «Génesis del azul modernista» en Estudios críticos sobre el Modernismo, op.cit.en la nota 14, pp. 168 a 173.

${ }^{30}$ Vid.Schumann, Iván A.: Op. cit. en la nota 17, p. 478. En esta obra todo el capítulo V está dedicado al simbolismo cromático, especialmente al color azul, pp. 471 a 480 . 
Gutiérrez Nájera atraído por el simbolismo de lo azul. No hay que olvidar que en 1876 conocía tanto la obra de Baudelaire como los valores simbólicos de belleza otorgados al azul por la poesía francesa.

Llegamos así al final de este recorrido a través del color en el modernismo y tal vez nada mejor para poner el punto final que esta hermosa frase del poeta Nájera en el primer número de su revista.

«El azul no es sólo un color; es un misterio...una virginidad intacta» ${ }^{21}$.

\section{REFERENCIAS BIBLIOGRÁFICAS}

BALAKIAN, Anna. 1969. El movimiento simbolista, Madrid, Ediciones Guadarrama.

BAudelaire, Charles. 1985. «Correspondencias», Las flores del mal, Madrid, EDAF, pp. 34 a 36.

CRESPO, Angel. 1974. Juan Ramón Jiménez y la pintura, Puerto Rico, Editorial Universitaria.

DARío, Rubén. 7 diciembre 1886. «El pájaro azul». La Epoca, Santiago de Chile.

- 2 octubre 1887. «El velo de la reina Mab». La Epoca, Santiago de Chile.

- 1919. «Cantos de Vida y Esperanza» en Historia de mis libros, Obras Completas, Vol.XVII, Madrid, ed. Mundo Latino, p. 206, pp. 170 a 172.

- 1961. Poesías completas, «Epístolas y poemas» $9^{\mathrm{a}}$ ed., Madrid, Aguilar, p. 428

- 1990. «Palacio del sol», «Ideal», «Anagke», Azul, Barcelona, Ediciones 29, pp. 43 a $47,71,105$ a 107.

FÉRNÁNDEZ Molina, Antonio. 1981. Antología de la poesía modernista, Madrid, Ed. Júcar, pp. 31 y s.s.

${ }^{21}$ Cfr. Schulmann, Iván A.: Op. cit. en la nota 19, p.183; Boyd G.Carter: «La revista Azul» en El Modernismo, edición de Lily Litvak, Madrid, Turus Ediciones, 1975, p.p.337 a 358 . En esta última obra el autor recoge una curiosa posible fuente del uso simbólico del vocablo azul en un poema de Antonio Fernández Grilo titulado «Tu traje azul» publicado en El siglo XIX, 24 de agosto de 1874 y que empieza: «Lo azul es lo impalpable, lo vago, misterioso...». En opinión de Carter, Manuel Gutiérrez pudo conocer este poema que influiría en su conciencia estética. 
GaUTIER, Thèophile. 1852. Esmaltes y Camafeos.

GHIL, René: Traité du verbe, 1886 y Méthode à l'oeuvre, 1891

GonCourt, Edmond et Jules de.: Journal, París, Robert Laffont, 1989, T. II, pp. 569-570.

GoNZÁlEZ, Angel. 1974. Juan Ramón Jiménez, Madrid.

GutiérReZ NÁJERA, Manuel. 1876. «El arte y el materialismo», El Correo Germánico Méjico.

- 1876. «Luz y sombra».

- 1880. Del libro azul.

Henríquez UrueñA, Max. 1962. Breve historia del Modernismo, Fondo de

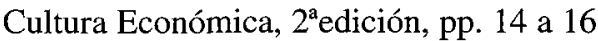

Huysmans, J.K. 1977 [1884] A Rebours, 2a ed., Ed. Gallimard.

- «L'Exposition des Independants», L'Art Moderne, Paris, 1883.

JECHSKE, Hans. 1954. La generación de 1898, Madrid, p. 123.

JIMÉNEZ, José Olivio (edición de). 1979. El Simbolismo, Madrid, Taurus Ediciones.

JiMÉNEZ, Juan Ramón. «Mar de pintor», Diario.

LEROY, Louis. 1874. «Exposition des Impressionnistes», Le Charivari, 25 abril.

LiTVAK, Lily. 1975. El Modernismo. Madrid, Taurus Ediciones, pp. 340 a 342.

- 1979. Erotismo fin de siglo, Antoni Bosch, editor, Barcelona. El Modernismo.

LORENZ, Erika. 1960. Rubén Darío, «bajo el divino imperio de la música», Managua, Ediciones Lengua.

Magnus, Hugo. Histoire de l'évolution du sens des couleurs

MALLARMÉE, Stéphane. 30 septiembre 1876. «The impressionnistes and Édouard Manet», The Art Monthly Review, Londres. 
MarTí, José. 1955. Sección constante, ed. Pedro Grases, Caracas, Imprenta Nacional, p. 26.

Michaud, Guy. 1947. Message poétique du Symbolisme, París, Nizet, pp. 256 a 258

NoRdau, Max. Degeneración, Madrid, Librería de Fernando Fé, T. I.

PORTAL, Fréderic. [1839] 1989 El simbolismo de los colores, Palma de Mallorca, Ediciones de la Tradición Unánime, pp. 71 a 81.

QUINET. 1841. Le Génie des Religions

Rrout, Denis. 1989. Les écrivains devant l'impressionnisme, Paris, Ed. Macula, p. 362 .

Schulman, Iván A. 1966. Génesis del Modernismo, El Colegio de México/Washington University Press, pp. 37 a 39-59

- 1960. Símbolo y color en la obra de José Martí, Madrid, Editorial Gredos, p. 472.

SiLVA CAStro, Raúl. El ciclo de lo «azul» en Rubén Darío. Recogido en Estudios críticos sobre el Modernismo. 1968. Edición de Homero Castillo, Madrid, Editorial Gredos.

Unamuno, Miguel de. 1984. El Cristo de Velázquez. Madrid, Espasa Calpe, pp. 17 y 22 .

VALLE-INCLÁN, Ramón del. La lámpara maravillosa, Madrid, Espasa-Calpe, $3^{\mathrm{a}}$ edición, p. 54.

- 1902. Corte de amor.

VARELA, Juan. 22 octubre 1888. Cartas Americanas. Recogidas en Darío, R.: $A z u l$, Obras Completas, Vol. IV, Madrid, Mundo Latino, pp. V-VI.

VERHAEREN, Émile. 15 junio 1885. «Exposition d'oeuvres Impressionnistes», Le Journal de Bruxelles. 